\title{
DAS GIDADES ÀS GONFEDERAÇÕES: GAMINHOS PARA SUPERAR OS GONFLITOS E AS GUERRAS QUE AMEAÇAM A INDEPENDÊNCIA DOS POVOS $^{12}$
}

\author{
Evaldo Becker (UFS) ${ }^{3}$ \\ evaldobecker@gmail.com
}

Resumo: O presente artigo tem como principais objetivos compreender melhor as discussões modernas acerca dos conflitos internos que ameaçam a vida política das cidades ou Estados; e de um ponto de vista externo, apresentar algumas das principais ideias construídas no período para alargar os laços exteriores dos povos na tentativa de superar e sobreviver às guerras que ameaçam a sobrevivência de povos e Estados. Para tanto, verificaremos de que maneira Bolívar recebe e oxigena as ideias acerca da guerra e da paz apresentadas por autores como Rousseau e o abade de Saint-Pierre, por exemplo.

Palavras-chave: Cidades. Confederações. Conflitos. Independência.

O presente artigo tem como principais objetivos compreen-

\footnotetext{
${ }^{1}$ Recebido em: 30-04-2018/ Aprovado em: 08-01-2019/ Publicado on-line em: 01-02-2019.

${ }^{2} \mathrm{O}$ presente artigo é resultado tardio do projeto de Pós-doutorado intitulado "Rousseau e os limites da razão de Estado", desenvolvido entre os anos de 2014 e 2015, com bolsa da CAPES/Brasil, junto à Université du Québec à Trois-Rivières - UQTR, sob a supervisão dos Professores Dr. Sebastién Charles e Dra. Syliane Malinowski -Charles. Ele integra também um projeto maior, intitulado "Rousseau e as Relações Internacionais na Modernidade", financiado pela FAPITEC /SE e pelo CNPq.

${ }^{3}$ Evaldo Becker é Professor do Departamento de Filosofia da Universidade Federal de Sergipe, Aracaju, SE, Brasil.
} 
der melhor as discussões modernas acerca dos conflitos internos que ameaçam a vida política das cidades ou Estados; e de um ponto de vista externo, apresentar algumas das principais ideias construídas no período para alargar os laços exteriores dos povos na tentativa de superar e sobreviver às guerras que ameaçam a sobrevivência de povos e Estados. Para tanto, verificaremos de que maneira Bolívar recebe e oxigena as ideias acerca da guerra e da paz apresentadas por autores como Rousseau e o abade de Saint-Pierre, por exemplo.

Inicialmente é preciso tentar circunscrever e aclarar o próprio conceito de cidade, haja vista que o mesmo passa por transformações substanciais ao longo da história do ocidente, designando desde as cidades-estados gregas individuais, como Esparta e Atenas, por exemplo, mas chegando até mesmo a designar aquilo que se convencionou chamar de Estado ou República. No artigo "Cidade" escrito por Diderot e publicado no volume 3 da Encyclopédie, por exemplo, podemos ler: "Outrora, a palavra cidade designava um Estado, um povo com todas as suas dependências, uma república particular. Hoje em dia, essa denominação só convém a algumas cidades da Alemanha ou dos cantões suíços" (DIDEROT, 2015, p. 67).

Rousseau constrói suas ideias acerca da organização política interna dos corpos políticos e das relações internacionais com o auxílio das teorias de Hobbes e do abade de Saint Pierre, dentre outros. Estas ideias por sua vez, serão recebidas e oxigenadas por líderes políticos revolucionários das Américas, dentre eles Simón Bolívar, que se servirá delas para pensar um modelo de federação para a América Latina que respeite as peculiaridades dos povos que aqui habitam.

Um dos "maiores gênios" da teoria política que tratou 
das questões ligadas à manutenção da paz e da autonomia das cidades ou Estados foi o Inglês Thomas Hobbes. Repassaremos de maneira sumária alguns dos argumentos hobbesianos relativos ao estabelecimento da paz e de seus limites na arena internacional. Tais argumentos servirão para melhor compreendermos o panorama político que estava diante de Rousseau e Saint-Pierre quando estes elaboravam suas próprias ideias políticas no século XVIII.

\section{HOBBES E A GUERRA INSUPERÁVEL}

Thomas Hobbes pretendia fazer uma verdadeira ciência política e nos deixou importantes reflexões sobre o modo de proceder dos homens na busca pela paz e pela ordem nas sociedades por eles formadas. Hobbes opta claramente pela paz como sendo o valor fundamental dos corpos políticos. Mesmo que para alcançá-la sejam necessárias medidas violentas e impopulares. Hobbes analisará o suposto estado de natureza que antecede o estabelecimento das sociedades como sendo um estado de guerra e violência onde "o homem é o lobo do homem", e que deve ser abandonado em favor do estabelecimento da paz, da ordem e de todas as comodidades da vida civil. Esta parece ser uma das interpretações mais corriqueiras e inquestionáveis da obra do filósofo de Malmesbury. Contudo, conforme já alertamos em outro artigo $^{4}$, uma leitura atenta de seus textos, pode nos conduzir à

\footnotetext{
${ }^{4}$ Em nosso artigo "Rousseau e as relações internacionais na modernidade", publicado nos Cadernos de Ética e Filosofia Política, em 2010, alertávamos para a necessidade de contextualizar melhor a tese de que "o homem é o lobo do homem" em Hobbes, sobretudo no que concerne ao seu aspecto internacional. Para maiores detalhes, ver: BECKER, Evaldo. Rousseau e as relações internacionais na modernidade. In: Cadernos de Ética e Filosofia Política, n. 16, vol,1, 2010. https://www.revistas.usp.br/cefp/article/view/82590/85553, acesso em 25/04/2018.
} 
problematização desta compreensão. Na epístola dedicatória de seu livro Do cidadão o autor escreve:

Para ser imparcial, ambos os ditos são certos - que o homem é um deus para o homem, e que o homem é o lobo do homem. O primeiro é verdade, se comparamos os cidadãos entre si; e o segundo, se cotejamos as cidades. Num, há alguma analogia e semelhança com a Divindade, através da Justiça e da Caridade, irmãs gêmeas da paz; no outro, porém, as pessoas de bem devem defender-se usando, como santuário, as duas filhas da guerra, a mentira e a violência - ou seja, para falar sem rodeios, recorrendo à mesma rapina das feras (HOBBES, 2002, p. 3, grifo nosso).

Como fica evidente na passagem acima, a ideia segundo a qual o homem é o lobo do homem não vale para os homens tomados individualmente, para estes o que vale é a compreensão de que o "homem é um Deus para o homem"; é no que toca à relação estabelecida entre as cidades que vale a analogia com o lobo. Nesse sentido, conforme indicamos no artigo acima mencionado, talvez fosse mais correto dizer que "as cidades são o lobo das cidades" ou mesmo que "os Estados são os lobos dos Estados”. O nível externo do relacionamento entre os Estados é marcado pela guerra, senão em ato, ao menos em potência, no que foi designado como "estado de guerra". Para Hobbes os soberanos encontramse em estado de natureza, e não podem haver leis que os limitem sob pena de fazer com que estes deixem de sê-lo. Poderíamos resumir a tese de Hobbes através da seguinte fórmula:

$$
\mathrm{EN}=\mathrm{EG}=\mathrm{RI}
$$

O Estado de Natureza é igual ao Estado de Guerra que é igual à situação das Relações Internacionais na qual se encontram os Estados. Esta situação, no caso de Hobbes, é infelizmente irremediável. Já que o governante é tido como soberano e é posto acima das leis, a situação de anomia das 
relações internacionais é permanente e insuperável. E neste nível, a rapina, o uso da força e da violência são "naturais", sendo mesmo concebidas como atividades econômicas.

No nível interno, uma série de violências também são autorizadas e para se constituir uma cidade ou república, é necessário que os homens abram mão de sua liberdade irrestrita e que se dobrem à vontade do governante. Em Hobbes a razão de Estado é a própria razão do governante à qual devem se submeter todas as razões particulares. No Do cidadão Hobbes afirma que uma pessoa, um ente de razão como a cidade, existe quando as vontades de muitos estão contidas na de um só, de tal modo que este pode usar a força de todos os servos segundo "sua própria vontade e prazer" (HOBBES, 2002, p. 159).

Essa associação que pode ser formada por um governante e por súditos, pode se estabelecer por instituição livre ou mesmo pela força que obriga um amontoado de homens a viver sob a lei de um chefe. Uma multidão de servos pode sim ser considerada, segundo Hobbes, como sendo um ‘povo' ou uma ‘cidade'. É exatamente o que ele defende no capítulo IX de seu Do cidadão. Vejamos:

Devemos refutar a opinião daqueles para quem não é uma cidade a que se formar de servos - por maior que seja o seu número - sob um senhor comum. [...] Segue-se, portanto que necessariamente deve constituir uma cidade aquela que se forma de um senhor e de muitos servos. E não há razão alguma que possa contradizê-lo (HOBBES, 2002 , p. 159, grifo nosso).

Contudo, mesmo que Hobbes autorize a violência e a força na constituição dos corpos políticos, ele, que buscava o estabelecimento da paz e da ordem nas cidades para que pudéssemos gozar das benesses da civilização, não deixa de salientar e apontar para aqueles que ele considera como 
sendo os responsáveis pela emergência das guerras e perturbações. Observemos o que escreve o filósofo inglês:

Assim, uma pedra que por suas formas angulares e ásperas tira mais espaço das outras do que ela própria preenche, e que devido à rigidez de sua matéria não pode ser reduzida em tamanho, nem cortada, e por isso pode fazer que a edificação não seja tão compacta quanto precisa ser, é descartada, por não ter serventia; da mesma forma, costuma-se dizer que é um inútil, e perturbador dos demais, aquele homem que tenha uma grosseira disposição a tomar para si o que é supérfluo, a privar os outros do que é necessário, e a quem é impossível corrigir racionalmente, tão teimosas são suas afeições.

Ora, como cada um tem, não apenas por direito, mas também por necessidade natural, de usar o máximo de sua força para conseguir as coisas necessárias para sua conservação - se qualquer outro se bater contra ele por coisas supérfluas, será por culpa deste último que brotará a guerra (HOBBES, (1642) 2002, p. 60).

Como se pode perceber, mesmo Hobbes com toda a autorização de violências que concede aos governantes, tem clareza acerca das responsabilidades pela emergência dos conflitos e das guerras no interior dos corpos políticos. Estes são gerados pela sanha de acumulação e de luxo de alguns em detrimento do mínimo necessário à sobrevivência de muitos. A desigualdade extrema ameaça a sobrevivência das cidades ou repúblicas e é o móvel dos distúrbios ocorridos em seu seio.

\section{ROUSSEAU: POLÍTICA INTERNA E EXTERIOR}

Tendo repassado sumariamente alguns elementos da teoria política de Hobbes, passemos agora, brevemente, à compreensão de Rousseau acerca da política interna e exterior. Nos Princípios do direito da guerra, texto que integraria as suas Instituições Políticas, o autor escreve:

[...] vejo povos infortunados gemendo sob um jugo de ferro, o gênero 
humano esmagado por um punhado de opressores, uma multidão sobrecarregada de trabalho e faminta por pão, de quem o rico bebe em paz o sangue e as lágrimas, e em todo lugar o forte armado contra o fraco do temível poder das leis. Tudo isso se faz pacificamente e sem resistência: é a tranquilidade dos companheiros de Ulisses trancados na caverna do Ciclope, esperando para serem devorados (ROUSSEAU, 2011, p. 154).

Já no início dos Princípios do direito da guerra o autor ironiza a pretensa paz propiciada por meio do estabelecimento dos Estados particulares e de suas instituições públicas. Ele contrapõe às máximas dos filósofos e dos jurisconsultos as observações da situação vivenciada de fato pelos povos. Em resposta óbvia à ideia hobbesiana de que a paz é estabelecida através da instituição do pacto social, Rousseau advogará que é com o estabelecimento das sociedades particulares que se deflagra o mais terrível estado de guerra tanto internamente quanto entre as nações.

É precisamente contra os autores, que para agradar os Príncipes e os poderosos, despojam o povo de todas as suas prerrogativas, que se construirá a argumentação de Rousseau nos Princípios do direito da guerra. Limitar-me-ei como sempre fiz, escreve Rousseau, "a examinar os estabelecimentos humanos por seus princípios, a corrigir, se for possível, as falsas ideias que nos dão os autores interesseiros; e a fazer ao menos com que a injustiça e a violência não tomem sem pudor o nome de direito e de equidade" (ROUSSEAU, 2011, p. 154).

Dentre as ideias falsas oferecidas por autores como Hobbes e Grotius, considerados por ele como sendo autores interesseiros, podemos citar aquelas concernentes à organização interna de um estado legítimo, que Rousseau já havia examinado de forma detida no Contrato Social e que seriam completadas na segunda parte de suas Instituições políticas, 
caso esta obra tivesse sido concluída. Após ter negado veementemente as teorias de Grotius e de Hobbes acerca da escravidão voluntária no capítulo IV, Rousseau afirmará no capítulo V do Contrato que:

Haverá sempre uma grande diferença entre subjugar uma multidão e reger uma sociedade. Sejam homens isolados, quantos possam ser submetidos sucessivamente a um só, e não verei nisso senão um senhor e escravos, de modo algum considerando-os um povo e seu chefe. Trata-se, caso se queira, de uma agregação, mas não de uma associação; nela não existe nem bem público, nem corpo político. Mesmo que tal homem domine a metade do mundo, sempre será um particular; seu interesse, isolado do dos outros, será sempre um interesse privado (ROUSSEAU, OC, III, p. 359).

O que se percebe na passagem acima é que em tais ajuntamentos humanos não há vontade geral, não há fỉm público almejado. Vários são os comentadores que observaram que para Rousseau não basta apenas amontoar um bando de homens em um canto qualquer do planeta para formar um povo. Em seu artigo Rousseau: peuple et frontières Vargas (2001, p. 58), precisa que "a fronteira pode ser o encerramento de um povo sobre um território cercado pela força militar, policial, que ocupa os lugares e que submete os habitantes aos rigores de uma mesma lei". Mas tal ajuntamento não passa aos olhos de Rousseau, de uma agregação, estendida aqui de forma pejorativa e em contraposição ao que ele considera uma verdadeira associação que dá origem à cidade ou república. Esta, para ser legítima, para constituir verdadeiramente um povo, deve ser regida por leis justas e ter em vista apenas o benefício comum e não a vontade aleatória e arbitrária dos chefes.

Chegado o momento em que nossas forças não bastavam para subsistirmos isoladamente, é hora de estabelecer 
uma forma de associação que seja benéfica para todos os associados. Tal coisa só pode se dar através de um verdadeiro contrato social, que "defenda e proteja a pessoa de cada associado com toda a força comum, e pela qual, cada um, unindo-se a todos, só obedece, contudo, a si mesmo permanecendo assim tão livre quanto antes" (ROUSSEAU, OC, III, 1964, p. 360). Este contrato é descrito da seguinte maneira:

Este ato de associação produz, em lugar da pessoa particular de cada contratante, um corpo moral e coletivo, composto de tantos membros quantas são as vozes da assembleia, e que, por esse mesmo ato ganha sua unidade, seu eu comum, sua vida e sua vontade. Essa pessoa pública, que se forma, desse modo, pela união de todas as outras, tomava antigamente o nome de $\operatorname{Cidade}^{5}$ e, hoje, o de república ou de corpo político, o qual é chamado por seus membros de Estado quando passivo, Soberano quando ativo, e Potência quando comparado com seus semelhantes. Quanto aos associados, recebem eles coletivamente o nome de povo e se chamam, em particular, cidadãos enquanto partícipes da autoridade soberana, e súditos enquanto submetidos às leis do Estado (ROUSSEAU, OC, III, p. 361 - 362, tradução e grifo nossos).

\footnotetext{
${ }^{5}$ É interessante notarmos a atenção e precisão de Rousseau no que concerne ao termo Cidade, redigido por ele como “Cité”, em Francês. Rousseau considera a cidade, não como sendo os prédios e construções, mas a união ativa dos cidadãos. Segue agora a longa nota aberta por ele, exatamente junto ao termo mencionado. Utilizaremos para tanto a tradução de Lourdes Santos Machado, na Edição da Editora Globo de 1962. "O verdadeiro sentido dessa palavra quase que se perdeu inteiramente entre os modernos. A maioria considera um burgo como sendo uma cidade e um burguês como um cidadão. Não sabem que as casas formam o burgo, mas que são os cidadãos que fazem a cidade. Esse mesmo erro custou caro, outrora, aos cartagineses. Não sei de jamais haver-se dado o título de cives ao súdito de qualquer príncipe, nem mesmo antigamente entre os macedônios, nem atualmente entre os ingleses, se bem que estes se encontrem muito mais próximos da liberdade do que todos os demais. Somente os franceses tomam com familiaridade o título de cidadãos porque, como se pode ver nos seus dicionários, não dispõem da verdadeira noção do significado do termo, sem o que praticariam, por usurpá-lo, o crime de lesa-majestade. Essa palavra, para eles, exprime uma virtude e não um direito. Quando Bodin quis falar de nossos cidadãos e burgueses, incorreu em sérios erros, tomando uns pelos outros. O Sr. D’Alembert não se enganou nesse particular e distinguiu muito bem, em seu artigo 'Genebra', as quatro ordens de homens (que podem ser cinco, se nelas incluírem os simples estrangeiros) que existem no nosso burgo e das quais somente duas compõem a república. Nenhum outro autor francês, que eu saiba, compreendeu o sentido verdadeiro da palavra cidadão (ROUSSEAU, 1962, p. 28).
} 
É importante perceber como Rousseau distingue os conceitos de Soberano e de Governo. Para que as leis estabelecidas sejam justas, elas devem ser estabelecidas ou ao menos ratificadas pelo Soberano. Quanto a saber quem participa dele, a resposta é evidente. Do Soberano fazem parte o conjunto do povo reunido, 'todas as vozes da assembleia'. Quanto aos membros do governo, o príncipe ou os magistrados, estes "são os depositários do poder executivo, não são senhores do povo, mas seus oficiais [empregados diríamos nós]; que este pode nomeá-los ou destituí-los quando lhe aprouver" (2001, p. 120).

Os magistrados, ou governantes, devem estar sob o jugo da lei como todos os demais cidadãos e não como em Hobbes, por exemplo, onde o governante encarna a própria cidade e não pode estar submetido à nenhuma lei. Nos Princípios do direito da guerra o autor afirma que para a perfeição da ordem social é preciso que a lei dirija a força, e que "nas ideias de independência absoluta dos príncipes" é somente a força quem fala. Disfarçada sob o nome de lei ela fala aos cidadãos e sob o nome de "razão de Estado" ela fala aos estrangeiros. "De sorte que o vão nome de justiça serve em toda a parte apenas de salvaguarda à violência" (ROUSSEAU, 2011, p. 155).

Em seu entender a maioria das guerras é deflagrada por ninharias, pela ambição ou pelas paixões dos governantes. Nesse sentido, é preciso saber se em termos de legitimidade estes estão ou não submetidos às leis do Estado. Pois, se o Príncipe ${ }^{6}$ está submetido às leis do Estado, "sua pessoa está

\footnotetext{
${ }^{6}$ Importa esclarecer ao leitor contemporâneo e, sobretudo, àqueles que não estão familiarizados com a linguagem rousseauniana que o autor utiliza o termo Príncipe, em um sentido bastante preciso ao longo de sua obra. O conceito de Príncipe está próximo daquele que hoje nos chamaríamos de Governo. Vejamos, por exemplo, a definição apresentada por Rousseau no Emílio: "Segue-se
} 
ligada e sua vida pertence ao Estado, como aquela do último Cidadão. Mas se o Príncipe está acima das leis, ele vive no puro estado de natureza e não deve prestar contas nem a seus súditos nem a ninguém, de nenhuma de suas ações" (ROUSSEAU, 2011, p. 160). E este é o principal motivo desta peste que é a guerra, que apesar de ser gerada pela ambição de poucos é paga com o sacrifício dos muitos que jamais serão beneficiados.

Comuns em seu tempo e talvez mais ainda no nosso, são os combates, as conquistas e as invasões que tem por finalidade última, - independente das justificativas públicas apresentadas - apenas a pilhagem de recursos necessários ao invasor, sejam eles, bem alimentícios e ouro, como no passado, ou como atualmente, os diamantes, o petróleo e a água. Nesse sentido, denunciando a baixa avidez e a cobiça, que são os verdadeiros móveis das "guerras", Rousseau afirma:

A terra, o dinheiro, os homens e todos os despojos de que se pode apropriar-se se tornam assim os principais objetivos das hostilidades recíprocas, e esta baixa avidez, mudando insensivelmente as ideias das coisas, a guerra, enfim, degenera em pilhagem, e de inimigos e guerreiros tornamo-nos pouco a pouco tiranos e ladrões (ROUSSEAU, 2011, p. 165).

O grande perigo e talvez o maior de todos eles, que ronda constantemente nosso convívio coletivo, é a tentativa que parcelas corruptas do governo empreendem no sentido de usurpar o poder do povo e de legislar em causa própria e

das considerações precedentes que há no Estado um corpo intermediário entre os súditos e o soberano, e esse corpo intermediário, formado por um ou mais membros, é o encarregado da administração pública, da execução das leis e da manutenção da liberdade civil e política. Os membros desse corpo chamam-se magistrados ou reis, isto é, governadores. O corpo inteiro, considerado pelos homens que o compõem, chama-se príncipe e, considerado por sua ação, chama-se governo". (ROUSSEAU, Emílio, 1999, p.655). 
não mais em prol da coletividade. Se a administração pública for delegada a magistrados mercenários e corrompidos a tendência é que a soberania seja usurpada e que se agravem as desigualdades até o ponto extremo do domínio e da violência contra seus próprios concidadãos.

Uma maneira segura de reduzir os problemas decorrentes das relações externas, geralmente belicosas, é uma boa organização interna na qual todos, inclusive os governantes, estejam submetidos a leis justas. Afinal, não são raras as vezes em que parcelas interesseiras e corruptas dos governos se servem de ameaças externas para empreender a opressão e a retirada de direitos civis. Tal processo já havia sido narrado ao final do Discurso sobre a desigualdade da seguinte maneira:

Ver-se-ia a multidão oprimida interiormente em consequência das próprias precauções tomadas contra o que a ameaçava de fora; verse-ia a opressão crescer continuamente sem que os oprimidos jamais pudessem saber que termo teria, nem que meios legítimos lhes restariam para contê-la; ver-se-iam os direitos dos cidadãos e as liberdades nacionais extinguirem-se pouco a pouco, e as reclamações dos fracos serem consideradas como murmúrios sediciosos, ver-se-ia a política restringir a uma porção mercenária do povo a honra de defender a causa comum [...]; ver-se-iam os defensores da pátria tornarem-se, cedo ou tarde, seus inimigos, e terem continuamente um punhal erguido contra seus concidadãos (ROUSSEAU, 1989, p. 114, grifo nosso).

Quando nossos governantes (funcionários) ganham para nos roubar e violentar, nos parece ser sinal suficiente de que atingimos graus elevados de corrupção e de ameaça à república e à cidadania ${ }^{7}$. Este é o ponto em que seus desmandos acabam por decretar de fato a morte da cidadania

7 Conforme Rousseau: “[...] Os deveres do cidadão devem vir antes dos do senador, e os do homem, antes dos do cidadão: mas, infelizmente, o interesse pessoal está sempre em razão inversa do dever 
e o rompimento do pacto social.

No que concerne à defesa comum dos povos e territórios quando estes são ameaçados por potências poderosas, Rousseau havia examinado a possibilidade do estabelecimento de ligas federativas defensivas que mantivessem a autonomia e independência internas, mas que fossem fortalecidas externamente. Seu pensamento, assim como o dos autores que examinamos acima foram conhecidos e meditados por pensadores latino americanos, como Simón Bolívar, que lutaram para que a rapina das terras da América Latina e a opressão de seus povos fosse finalmente interrompida e desse lugar à uma Nação forte e independente, que respeitasse seus povos e lutasse por seu bem-estar.

\section{BOLÍVAR: HERDEIRO DA FILOSOFIA DAS LUZES}

Bolívar nasceu em Caracas, em 1783. Filho de espanhóis, nascido no novo mundo, foi uma figura híbrida, mistura de europeu e americano, carregou sempre consigo este caráter distinto, original. Misto de filósofo, guerreiro e diplomata que lutou tenazmente pela liberdade a partir das armas intelectuais do Velho Mundo, afiadas nas peleias e experiências do Novo. Dentre os mestres que teve destaca-se a figura de Simón Rodríguez, carinhosamente chamado por ele de “Robinson”, em alusão ao personagem Robinson Crusoé, cujo livro de título homônimo, tem lugar especial na teoria rousseauniana.

Aliás, esta com certeza não é uma coincidência, afinal Simón Rodríguez era leitor e adepto da pedagogia de Rousseau e incutiu em seu pupilo muitas das ideias do filósofo

e aumenta na medida em que a associação se torna menor" (ROUSSEAU, Economia Política, 2006, p. 89). 
genebrino, em especial, diríamos, o amor pela igualdade e sobretudo pela liberdade. Dennis Wepman, em seu livro $\mathrm{Si}_{-}$ món Bolívar, afirma que Rodríguez seguiu a pedagogia rousseauista sobretudo no que concerne à crítica de uma educação livresca e ao cuidado com o fortalecimento do corpo. Vejamos:

Rodríguez adotou essa filosofia integralmente e educou o jovem Simón para pensar e agir espontaneamente, sem lhe encher a cabeça com informações inúteis. Ensinou-lhe a observar atentamente as coisas e a agir com base nos dados de suas observações. Aluno e professor mudaram-se de Caracas para o campo e, juntos, cavalgaram, nadaram e caminharam pelos campos. $\mathrm{O}$ corpo relativamente frágil do rapazinho tornou-se mais robusto e sua mente curiosa tornou-se mais ágil. Ele era o protótipo do estudante que deve ter povoado os sonhos de Rousseau (WEPMAN,1987, p. 15).

Este período inicial de formação rousseauísta campestre que durou cinco anos, foi interrompido em 1797 após Rodriguez ter-se envolvido em uma tentativa de revolução. Sua formação, mais autodidata que metódica continua. Mudanças de mestres, períodos de estudos autodidatas, além da frequentação dos Salões franceses, contribuíram para com sua formação social e política. Rafael Bernal Medina, em seu Ruta de Bolívar, descreve sua estadia na Europa no ano de 1804:

Se estabelece em Paris, onde leva uma vida de estudo e sociedade. Nos salões da metrópole da elegância, aprende sobre refinamento e galanteria, prendas sociais que, como sempre o decoram, atraem sutilmente as mulheres, as quais entretêm a parte secreta de sua história (MEDINA, 1961, p. 32, nossa tradução).

Mas a passagem de Bolívar pela Europa não é marcada apenas pela frequentação dos salões e da vida social na Cidade Luz. Conforme ele mesmo afirma em carta enviada ao general Francisco Santander, apesar dos questionamentos 
apresentados em sua época acerca de sua formação, talvez seus críticos não tivessem estudado tanto quanto ele:

Locke, Condillac, Buffon, D’Alembert, Helvetius, Montesquieu, Mably, Filangieri, Lalande, Rousseau, Voltaire, Rollin, Berthot e todos os clássicos da antiguidade, assim, filósofos, historiadores, oradores e poetas; e todos os clássicos modernos da Espanha, França e Itália e grande parte dos ingleses (BOLÍVAR, carta de 20 de maio de 1825. In: RODRÍGUEZ, 2001, p. 128 - nossa tradução).

Herdeiro do pensamento republicano das Luzes, mas também dos antigos, quando esteve em Milão e presenciou o ato autocrático de Napoleão, ao se coroar como rei, o jovem sul-americano teve seu espírito democrático chocado. E depois de outros périplos, já em companhia de seu antigo mestre, Simón Rodriguez, vai a Roma e diante do Monte Sacro faz seu famoso juramento prometendo não dar descanso a seus braços nem repouso à sua alma até que se tenham rompido as correntes que oprimem os povos da América. ${ }^{8}$

Mais que um ato de arrebatamento e descontrole, o juramento do Monte Sacro dá início a uma luta sem trégua em favor da liberdade da América. De retorno à Caracas, organiza reuniões patrióticas e em 1809, juntamente com seus companheiros, é processado como insurgente violento pelo governo colonial. Estava aberto o caminho para uma trajetória de lutas pela liberdade e pela unidade dos povos americanos.

\footnotetext{
${ }^{8}$ Seu mestre transmite à posteridade o conteúdo deste juramento, do qual extraímos a seguinte passagem, exposta nas belas páginas do Libro de Oro de Bolívar, de Cornélio Hispano: "Juro diante de você; juro pelo Deus de meus pais; juro por eles; juro por minha honra e juro por minha pátria, que não darei descanso a meus braços, nem repouso a minha alma, até que tenha rompido as correntes que nos oprimem pela vontade do poder espanhol" (HISPANO, 1980, p. 51, nossa tradução).
} 
Ele critica o modelo deturpado de contrato social imposto pela violência aos descobridores, conquistadores e povoadores da América, que os acorrenta aos interesses da metrópole . Lê o tratado de Vattel sobre $O$ direito das gentes ${ }^{10}$, que havia sido publicado em várias edições e era um texto amplamente utilizado e conhecido. Nele o "Libertador" pôde ler acerca dos principais objetivos de um bom governo, dentre eles: $1^{\circ}$ ) Prover às necessidades da nação, $2^{\circ}$ ) Procurar a Verdadeira Felicidade da Nação e $3^{\circ}$ ) Fortificarse Contra os Ataques Externos. Tais lições já eram evidentes nos séculos XVIII e XIX, mas são completamente ignoradas pelos atuais ocupantes do "governo" de nossa "República das Bananas", que abandonam os projetos de liga defensiva e de integração como a UNASUL ou o MERCOSUL, por exemplo, - que estão em plena consonância com o que prevê o artigo $4^{\circ}$ de nossa Constituição ${ }^{11}$ - em prol de posturas subservientes a interesses estrangeiros e privados, mas danosos ao nosso povo.

A América, berço de uma mistura de raças formada principalmente por índios, europeus e negros africanos, avança na luta pela liberdade e para escapar do jugo violento dos usurpadores. Percebendo que territórios isolados não

\footnotetext{
${ }^{9}$ Bolívar escreve na Carta da Jamaica: "O imperador Carlos V fez um pacto com os descobridores, conquistadores e povoadores da América, o qual, como diz Guerra, é nosso contrato social" (BOLÍVAR, Carta da Jamaica, 1992, p. 63).

10 "Así pues Bolívar, en su regreso de Europa, llega a América, influido no solamente por las ideas de Rousseau que hablaban de la bondad innata en el hombre y por el llamado equilibrio de poderes propagado por Montesquieu, sino, que a su vez, llegaba como lo hemos dicho, compenetrado de las ideas de Emmerich Vattel, quien dio en su vademécum de estadistas y hombres de gobierno, en 1758 titulado: 'Droit de gens', el más refinado canto a la igualdad" (LOZANO CLEVES, 1983, p. 193).

${ }^{11}$ A Constituição Brasileira de 1988, em seu Art. 4º $§$ Único, diz: “A República Federativa do Brasil buscará a integração econômica, política, social e cultural dos povos da América Latina, visando à formação de uma comunidade latino-americana de nações.” (BRASIL, 2009, p. 3).
} 
conseguiriam resistir à violência do experiente exército espanhol, Bolívar dedica sua vida ao ideal de uma confederação pan-americana ou Congresso Anfictiônico ${ }^{12}$, que libertasse a América da tirania espanhola ${ }^{13}$.

Desde a Carta da Jamaica, redigida em 1815, até os projetos Pan-Americanos de (1824-1826), Bolívar se esforça para erigir uma grande Federação Latino-Americana que pudesse garantir a independência, a liberdade e o bem-estar dos latino-americanos. Observemos como ele começa a delinear este projeto e como tem em mente, de forma crítica, os projetos de paz perpétua que eram discutidos na Europa:

Como seria belo se o istmo do Panamá fosse para nós o que o de Corinto foi para os gregos! Tomara que algum dia tenhamos a sorte de instalar ali um augusto congresso dos representantes das repúblicas, reinos e impérios para tratar e discutir os altos interesses da paz e da guerra com as nações das outras três partes do mundo. Essa espécie de corporação poderá ter lugar em alguma época feliz de nossa regeneração; outra esperança é infundada, semelhante à do abade de St. Pierre, que concebeu o louvável delírio de reunir um congresso europeu para decidir o destino e o interesse de suas nações (BOLÍVAR, Carta da Jamaica, 1992, p. 72).

\footnotetext{
${ }^{12}$ No que concerne à história e definição do termo Anfictionia, nos remetemos ao que informa Reza (2013), em seu livro A invenção da paz. Vejamos: “As primeiras ligas ou federações de povos ou estados acompanham a formação da civilização grega e a sua história se prolonga por quase 800 anos, entre os séculos VI a.C. e II d.C. Estas anfictionias, cujos delegados se reuniam em volta de um santuário comum, tinham como objetivo regulamentar as relações das tribos de uma nação outrora unificada. Segundo a lenda, a primeira liga foi organizada por Anfictião, filho de Prometeu, um dos heróis míticos da Grécia, e fazia parte de uma assembleia onde eram aprovadas as regras de segurança e de vinculação recíproca, incluindose a proteção dos santuários e a celebração de ritos e jogos esportivos. A sua mensagem era a mesma que a das anfictionias posteriores: fazer menos frequentes as guerras através de acordos que apelavam à comunidade de interesses dos confederados, a sua continuidade geográfica e à identidade cultural, religiosa e sanguínea dos seus habitantes." (REZA, 2013, p.11) "Em 388 a.C., o rei Filipe II da Macedônia organizou a mais famosa e sofisticada das anfictionias, a Liga helênica, com sede no Isto de Corinto. A sua criação sintetizou as tradições institucionais e intelectuais da Grécia, dando-lhe ênfase aos objetos de paz geral, união pan-helênica, coesão interna diante dos desafios externos e maior autoridade do órgão central sobre os estados membros" (REZA, 2013, p. 13-14)

${ }^{13}$ Ninguna idea que arraigara tan profundamente en el alma de libertador, después de la libertad, que la de la unidad americana. Bolívar tuvo una visión nítida y precisa del futuro de América, y previó sus altos destinos sujetos, desde luego, al cumplimiento de ciertas condiciones sin las cuales no sería posible cumplir ese destino. Una de esas condiciones, esencial según el mismo Libertador, era el de la unidad de los pueblos americanos (LOZANO CLEVES, 1983, p. 99).
} 
A passagem acima mostra bem duas das matrizes teóricas que povoam o ideário de Bolívar. Incialmente, o que se percebe é a filliação à mais antiga forma ocidental de integração de Cidades-Estado, as anfictionias, que congregavam as cidades gregas em torno do istmo de Corinto. Bolívar anseia para que o istmo do Panamá seja a sede de um Congresso Mundial que discuta a paz e a guerra entre os povos. Por outro lado, mostra o conhecimento do Projeto para tornar perpétua a paz na Europa, redigido pelo abade de SaintPierre e que foi resumido e comentado por Rousseau. Projeto este que prevê a criação de uma "Uma liga dos príncipes cristãos", que confere todo poder aos chefes e deixa os povos à sua mercê.

Tal perigo, percebido também por Rousseau e exposto em seus escritos sobre Saint-Pierre, talvez tenham feito com que Bolívar evitasse o modelo criado na Europa. O que transparece nos escritos do Libertador é o desejo de ver os povos da América livres, respeitados e com uma legislação condizente com suas características próprias.

Quando redige a Carta da Jamaica em 1815, Bolívar tem plena consciência da necessidade de autonomia dos povos da América, está convicto também da necessidade de pensar em legislações que sejam adequadas aos anseios de nossos povos e não de leis que nos acorrentem a interesses alheios. Vejamos o que nos diz Lozano Cleves: "Citando Montesquieu, afirma que as leis devem ser relativas a topografia do país, ao clima, a qualidade do terreno, ao gênero de vida dos povos e a seus costumes. Eis aqui, exclama, o Código que devemos consultar e não o de Washington” (1983, p. 163).

Dá-se assim, uma busca pelo aperfeiçoamento das relações internacionais, na direção de uma maior consideração 
aos direitos humanos e do interesse dos povos. Evidentemente que não se trata de criar aqui um império, mas de formar um robusto bloco defensivo, que salvaguarde a liberdade, a igualdade e o bem-estar dos povos latino americanos.

Enquanto que o individualismo mais feroz e a razão de estado eram os únicos critérios da política europeia; a hispano américa introduzia nas relações internacionais uma consideração, antes de tudo os interesses supremos da comunidade jurídica, devendo o individualismo ceder espaço à solidariedade e à cooperação (CLEVES, 1983, p. 181 - nossa tradução).

Bolívar desenvolveu o ideal de construção de uma verdadeira "Nação Latino-Americana", uma liga federativa que não seguia simplesmente os moldes forjados na Europa, como dissemos acima, mas que levava em consideração as peculiaridades dos povos da América, organizada com base em seus próprios interesses e voltada para a construção do bem-estar de seu povo.

O Libertador empreendeu e participou de uma centena de batalhas. Guerras nas quais visava fazer respeitar os direitos humanos e as leis do direito público, mesmo durante as batalhas, o chamado direito na guerra. Em seu Bolívar patriota e internacionalista, Lozano Cleves lembra que apesar de esporadicamente a história apresentar teses de filósofos e governantes acerca da unificação das nações, "quase todos estabeleciam este princípio para exercitar um cruel imperialismo contra os povos débeis", mas a ideia de Bolívar foi distinta:

Ele desejou e praticou o entendimento entre os povos da América, para que se colocassem em posição favorável de defesa, para o progresso recíproco, para a ajuda solidária, para o melhoramento material e cultural de todos. Bolívar lançava todo o peso de sua ideologia, de sua espada e de sua influência pessoal e política para infundir o 
espírito de liberdade, de dignidade humana de aproveitamento dos recursos naturais e da independência dos povos americanos (CLEVES, 1983, p. 103 - nossa tradução).

Ele pretendia que as riquezas naturais de nosso continente servissem para propiciar o bem-estar de nossos povos e não o deleite e o luxo de ministros e estrangeiros ${ }^{14}$. Mencionando a sanha mineradora que não saciava de buscar cada vez mais ouro nas terras do Novo Mundo, reduzindo seus povos às situações mais abjetas, Bolívar pergunta se “[...] pretender que um país tão felizmente constituído, extenso, rico e populoso seja meramente passivo, não é um ultraje e uma violação aos direitos humanos?" (BOLÍVAR, 1992, p. 62-63 - Carta da Jamaica). O que diria ele acerca da expulsão de povos indígenas para extração de minérios em áreas protegidas, da privatização da própria água, e mesmo da água das chuvas, em curso na América, em nossos dias?

\section{A AMÉRICA LATINA DE ONTEM E DE HOJE}

Suas ideias foram lidas e meditadas pelo ilustre político e pensador brasileiro, fundador da Universidade de Brasília, o saudoso Darcy Ribeiro. Este, ao final de seu visceral livro $O$ povo brasileiro, reafirma a ideia de que "Nosso destino é nos unificarmos com todos os latino-americanos por nossa oposição comum ao mesmo antagonista, que é a América anglosaxônica, para fundarmos, tal como ocorre na comunidade europeia, a Nação Latino-Americana sonhada por Bolívar" (RIBEIRO, 2006, p. 410-411).

\footnotetext{
14 "Desejo, mais do que ninguém, ver formar-se na América a maior nação do mundo, menos por sua extensão e riquezas que por sua liberdade e glória” (BOLÍVAR, 1992, p. 67 - Carta da Jamaica).
} 
Darcy considerava de forma positiva nossas potencialidades. Nossa juventude e nossa criatividade nos ajudariam a construir um gênero humano novo. Segundo ele, o que somos "é a nova Roma. Uma Roma tardia e tropical". Enfatizava o fato de que "O Brasil é já a maior das nações neolatinas, pela magnitude populacional e começa a sê-lo também por sua criatividade artística e cultural", mas lembrava da necessidade que temos agora de desenvolvermos "o domínio da tecnologia da futura civilização, para se fazer uma potência econômica, de progresso auto-sustentado" (RIBEIRO, 2006, p. 411). Darcy já repudiava o que voltamos a repudiar agora, qual seja, uma posição de atraso tecnológico, de desmonte da ciência e de aposta na venda de matérias-primas, que depois de transformadas enriquecerão ainda mais as nações desenvolvidas e nos deixarão na posição de vassalos, de povo explorado e incapaz de enriquecer com base na industrialização sustentável de seus ricos recursos naturais. Parece que andamos em círculos e que somos incapazes de adquirir a autonomia de que precisamos para nos tornarmos um verdadeiro país, pertencente à uma confederação latino-americana forte e independente.

Para que vivamos livres é preciso que formemos nosso povo para a liberdade. Caso contrário, esse mesmo povo cederá a propostas tirânicas e enganosas e comprará uma suposta paz em troca de sua liberdade. Nesse sentido, em seu Discurso de Angostura, proferido em 1819, Bolívar alertava para árdua tarefa dos legisladores da América, que teriam que legislar para homens "pervertidos pela ilusão do erro e por incentivos nocivos”. Em sua busca por uma formação libertadora, ele se voltava para as ideias do cidadão de Genebra. "A liberdade, diz, Rousseau, é um alimento suculento, mas de difícil digestão. Nossos malformados cidadãos 
terão de fortalecer seu espírito muito antes de conseguir digerir o saudável alimento da liberdade" (BOLÍVAR, Discurso de Angostura, 1992, p. 85).

Ainda no Discurso de Angostura, em tom iluminista e libertário, Bolívar criticava a escravidão reinante na América e enquanto Thomas Jefferson, presidente do Estado Unidos da América, convivia tranquilamente com os escravos de sua fazenda, o libertador alforriava os escravos e lutava contra o obscurantismo da escravidão. Em seu entender a escravidão seria fillha das trevas e "um povo ignorante é instrumento cego de sua própria destruição: a ambição e a intriga abusam de credulidade e da inexperiência de homens alheios a todo conhecimento político, econômico ou civil" (BOLÍVAR, Discurso de Angostura, 1992, p. 85).

$\mathrm{O}$ fato de Bolívar defender "com entusiasmo permanente”, conforme afirma Lozano Cleves (1983, p. 174) “a fundação de escolas, Universidades" a partir das quais a educação pública contribuiria para a emancipação moral dos povos, coloca-o a anos luz de nossos atuais "dirigentes", que apostam no desmonte da ciência e do conhecimento como sendo a forma mais rápida para impor normas contrárias à liberdade e ao bem-estar de nosso povo. Imbuídos que estão do desejo irrefreável de bajular povos estrangeiros e submeter sua própria nação à interesses estranhos.

Criticam bolívar pelo fato de que pela primeira vez alguém nascido nestas terras, com dinheiro e cultura, resolveu levantar a cabeça e depois a espada para pensar primeiramente nos povos do Novo Mundo e não em interesses alheios, por ter lutado pela liberdade, igualdade e indepen- 
dência dos povos e se negado a ser conivente com o parasitismo das elites que aqui habitavam e ainda habitam ${ }^{15}$.

Perdoem-me o tom um tanto ácido de minhas palavras, mas penso que o momento atual não se presta à plumas e paetês. Estamos imersos em tempos sombrios, em tempos de aumento das desigualdades, perda de liberdades e de direitos, tempos em que toda oportunidade é importante para reforçarmos nossa ânsia de liberdade, humanidade e justiça nestas terras de onde os direitos do homem e do cidadão parecem estar escapulindo. Espero, e aqui uma vez mais parafraseio o Libertador; que lutar pela liberdade e pela igualdade com justiça, não seja "arar no mar".

Nos tempos atuais, motivados por uma síndrome de capacho extrema e por uma ignorância crônica, determinados setores da direita brasileira, não são capazes sequer de ouvir

\footnotetext{
${ }^{15}$ Em seu Discurso de Angostura (1819), Bolívar alerta o povo para a necessidade de haver uma alternância no governo. Segundo ele: "A manutenção da autoridade num mesmo indivíduo tem acarretado, frequentemente, o fim dos governos democráticos. Eleições sucessivas são essenciais aos sistemas populares, porque nada é tão perigoso quanto deixar permanecer um mesmo cidadão por muito tempo no poder. O povo acostuma-se a obedecê-lo e ele, a mandar; isso dá origem à usurpação e à tirania" (BOLÍVAR, 1992, p. 83) A obra teórica e o exemplo prático de um incansável defensor da liberdade, serviu de inspiração para políticos e pensadores que defendiam e defendem a mesma causa. Para além de leituras caricaturadas do Libertador, tal como a do falecido presidente da Venezuela, Hugo Chavez, ou de críticos de direita, que sequer se dão ao trabalho de ler seus textos, antes de ridicularizá-lo, cito aqui alguns exemplos listados por Lozano Cleves, que servem sobretudo para aqueles que só consideram importante o que é dito ou escrito na América do Norte.

Depois de mencionar citações do Libertador feitas pelo presidente dos Estados Unidos Franklin D. Roosevelt, Lozano Cleves lembra que outro presidente do mesmo país, Kennedy, em muitas ocasiões citou Bolívar em seus discursos e transpõe a seguinte passagem de seu discurso: "Ciertamente a partir de hoy el sistema Interamericano no representa la unidad de gobierno, sino la unidad de pueblos; no sólo un enfoque común de metas políticas, sino un voto común para elevar el bienestar económico, social y político del hombre" (KENNEDY apud; LOZANO CLEVES, 1983, p. 105) E na sequência do texto apresenta outro trecho de um discurso de Kennedy, feito em frente à estátua de Bolívar em Washington. Ouçamos: "Bolívar con su percepción y genio procuro objetivos que nosotros nos esforzamos por lograr. Su sueño más grande fue el de la unión de defesa mutua de todas las repúblicas del hemisferio, contra la agresión de filósofos foráneos. Su alcance inspira la determinación de los estadistas de las Américas de hoy, de proteger de la usurpación extranjera su herencia de libertad, de elevar al máximo la grandeza espiritual y material de sus naciones; de extender a todos los americanos los beneficios de la libertad y de la justicia social; de hacer propia la guerra contra la pobreza, las enfermedades y la inhumanidad del hombre para con el hombre" (KENNEDY apud; LOZANO CLEVES, 1983, p. 106).
} 
falar em Bolívar, muito menos de ler e conhecer a ideias deste que foi um dos precursores dos movimentos libertários que visavam a autonomia e o bem-estar dos povos latinoamericanos. Nesse sentido, termino minha reflexão com estas palavras do Libertador, escritas na Carta da Jamaica em 1815, mas que soam extremamente atuais.

O véu rasgou-se, já vimos a luz e querem nos fazer voltar às trevas; romperam-se os grilhões; já fomos livres e nossos inimigos querem novamente escravizar-nos. Por tudo isso a América luta desesperadamente e, raras vezes, o desespero não leva consigo a vitória (BOLÍVAR, 1992, p. 55 Carta da Jamaica 1815).

Abstract: This paper aims at: presenting a panoramic view of modern discussions concerning internal conflicts which threaten and enrich the political life of cities, and, from an external point of view, to present some of the main ideas developed on that period to enlarge the exterior bonds of peoples, as an attempt to overcome or survive wars the threatened the independence of States. In order to achieve that goal, we have recourse to authors such as Machiavelli, Hobbes, Saint-Pierre, Rousseau and Bolívar.

Keywords: Cities. Confederations. Conflicts. Independence.

\section{REFERENNCIAS}

BECKER, Evaldo. Rousseau e as relações internacionais na modernidade. In: Cadernos de Ética e Filosofia Política, n. 16, vol. 1, 2010. https://www.revistas.usp.br/cefp/article/view/82590/85553, acesso em 25/04/2018.

BOLÍlVAR, Símon. Escritos Políticos. Tradução Jaques Mário Brand, Josely Vianna Baptista. Campinas, São Paulo: Editora da UNICAMP, 1992. (Coleção Repertórios).

. Discursos, proclamas y epistolario político. Edición preparada por M. Hernandez Sanchez-Barba. Madrid: Editora Nacional, 1978. 
BRASIL. Constituição da República Federativa do Brasil. $42^{\circ}$ ed. São Paulo: Saraiva, 2009.

CASTRO, Moacir Werneck de. Bolívar. São Paulo: Editora Três, 1973. (Biblioteca de História: Grandes personagens de todos os tempos, 9).

CLEVES, Alberto Lozano. Bolívar Patriota e Internacionalista. Bogotá: Imprenta y Publicaciones de las Fuerzas Militares. (Colección de Oro del Militar Colombiano, Vol. 11), 1983.

DIDEROT, Denis. Verbete Cidade. In: Enciclopédia, ou Dicionário razoado das ciências, das artes e dos ofícios. Volume 4 - Política. Denis Diderot, Jean Le Rond d'Alembert; organização Pedro Paulo Pimenta e Maria das Graças de Souza; tradução Maria das Graças de Souza, Pedro Paulo Pimenta e Thomaz Kawauche. São Paulo: Editora Unesp, 2015.

FREDRIGO, Fabiana de Souza. Guerras e Escritas: a correspondência de Simón Bolivar. São Paulo: Ed. UNESP, 2010.

HISPANO, Cornelio. El Libro de Oro de Bolívar. Medellín: Bedout, 1980.

HOBBES, Thomas. Do Cidadão. Tradução, apresentação e notas de Renato Janine Ribeiro. São Paulo: Martins Fontes, 2002.

MAQUIAVEL, Nicolau. Discursos sobre a primeira década de Tito Lívio. Tradução MF. Revisão técnica de Patrícia Fontoura Aranovich. São Paulo: Martins Fontes, 2007. 
POLIN, Raymond. L'invention par Machiavel du sens moderne du mot État. (Préface). In: GOYARD-FABRE, Simone (org.). L'État Moderne: regards sur la pensée politique de l'Europe occidentale entre 1715 et 1848. Paris: VRIN, 2000.

MEDINA, Rafael Bernal. Ruta de Bolivar: Espiritual y Geografica.3.ed. Cali - Colombia: [s.n.], 1961.207p.

RAMOS, Jorge Abelardo. História da nação Latino-americana. 2. ed. Florianópolis: Insular, 2012.

REZA, Germán A. de la. A invenção da paz: da República Cristã do duque de Sully à Federação das Nações de Simón Bolívar. Tradução Jorge Adelqui Cáceres Fernández. André Figueiredo Rodrigues. São Paulo: Humanitas, 2015.

RIBEIRO, Darcy. O povo brasileiro. São Paulo: Companhia das Letras, 2006.

Rousseau, Jean Jacques. Considerações Sobre o Governo da Polônia. In: Obras J.J. Rousseau, vol. II. Tradução de Loudes Santos Machado. Rio de Janeiro - Porto Alegre São Paulo: Editora Globo, 1962.

Discurso sobre a origem e os fundamentos da desigualdade entre os homens. Tradução de Iracema Gomes Soares e Maria Cristina Roveri Nagle. Brasília: Editora da Universidade de Brasília; São Paulo: Ática, 1989.

Do Contrato Social. In: Obras J.J. Rousseau, vol, II. Tradução de Loudes Santos Machado. Rio de Janeiro Porto Alegre - São Paulo: Editora Globo, 1962.

. Projeto de Constituição para a Córsega. In: Obras J.J. 
Rousseau, vol, II. Tradução de Loudes Santos Machado. Rio de Janeiro - Porto Alegre - São Paulo: Editora Globo, 1962.

. Princípios do direito da guerra. Tradução apresentação e notas de Evaldo Becker; Revisão da tradução de Ricardo Monteagudo. In: Trans/Form/Ação - Revista de Filosofia da UNESP, jul-ago, 2011 - ISSN - 1980-539X.

. Oeuvres complètes, t. I, II, III, IV e V. Paris : Bibliothèque de la Pléiade, 1959-1995.

ROZITCHNER, Leon. O Pensamento de Simon Rodriguez e a Revolução Pendente na América latina. In: COGGIOLA, Osvaldo (Org.) A revolução Francesa e seu Impacto na América Latina. São Paulo: Nova Stella; Editora Universidade de São Paulo; Brasília, DF: CNPq, 1990. p. 231-243.

RODRÍGUEZ, Simon. Cartas. Caracas: Universidad Nacional Experimental Simón Rodríguez, Ediciones del Rectorado, 2001.

SAINT-PIERRE, Abbé. Projeto para tornar perpétua a paz na Europa. Tradução de Sérgio Duarte. Prefácio de Ricardo Seitenfus. Brasília: Editora Universidade de Brasília, Instituto de Pesquisa de relações Internacionais; São Paulo: Imprensa Oficial do Estado de São Paulo, 2003.

VARGAS, Yves. Rousseau : peuple et frontières. In : JeanJacques Rousseau, Politique et Nation: Actes du II $^{\circ}$ Colloque international de Montmorency. Paris: Honoré Champion Editeur, 2001. 
VATTEL, Emmerich de. O Direito das Gentes ou Princípios da Lei Natural Aplicados à Condução e aos Negócios das Nações e dos Governantes. Tradução de Ciro Mioranza. Ijuí: Editora UNIJUÍ, 2008. 